Archives de sciences sociales des religions

112 | octobre-décembre 2000

Âme et corps : conceptions de la personne

\title{
MARTÍN MUÑOZ (Gemma), éd., Islam, Modernism and the West
}

Londres-New York, I.B. Tauris, 1999, 264 p. (bibliogr., index.)

Chantal Saint-Blancat

\section{OpenEdition}

\section{Journals}

Édition électronique

URL : http://journals.openedition.org/assr/20327

DOI : $10.4000 /$ assr.20327

ISSN : $1777-5825$

\section{Éditeur}

Éditions de l'EHESS

Édition imprimée

Date de publication : 31 décembre 2000

Pagination : 106

ISBN : 2-222-96698-1

ISSN : 0335-5985

\section{Référence électronique}

Chantal Saint-Blancat, « MARTín MUÑOZ (Gemma), éd. Islam, Modernism and the West », Archives de sciences sociales des religions [En ligne], 112 I octobre-décembre 2000, document 112.33, mis en ligne le 19 août 2009, consulté le 21 septembre 2020. URL : http://journals.openedition.org/assr/20327 ;

DOI : https://doi.org/10.4000/assr.20327

Ce document a été généré automatiquement le 21 septembre 2020

(c) Archives de sciences sociales des religions 


\title{
MARTÍN MUÑOZ (Gemma), éd., Islam, Modernism and the West
}

\author{
Londres-New York, I.B. Tauris, 1999, 264 p. (bibliogr., index.)
}

Chantal Saint-Blancat

\section{RÉFÉRENCE}

MARTÍN MUÑOZ (Gemma), éd., Islam, Modernism and the West, Londres-New York, I.B.

Tauris, 1999, 264 p. (bibliogr., index.)

1 L'introduction de G.M.M. à cet ouvrage collectif, publié sous sa direction, offre une perspective critique de l'analyse historique, politique et sociologique des relations entre l'islam et le monde occidental. Ce panorama stimulant souligne les risques d'une vision réductrice à la Huntington. Face à une interprétation tendancieuse de l'histoire musulmane, y compris celle plus récente de la mouvance islamiste, l'auteur suggère de réviser les instruments méthodologiques et d'abandonner une conception de l'Islam (avec I majuscule) qui, d'un côté, réduit celui-ci à une notion abstraite et immuable et d'un autre côté, sous-évalue la diversité historique et sociologique du monde musulman autant que les dynamiques liées aux transformations en cours. Elle met en garde contre l'effet de miroir (p.12), qui conduit le regard occidental à ne privilégier que les acteurs qui lui ressemblent, aux dépens d'une compréhension en profondeur des mouvements sociaux qui reflètent les réponses plurielles de la culture musulmane à la modernité. L'A. rappelle le rôle de l'islamisme dans l'émergence de la modernisation de l'expérience religieuse, comme celui des femmes et des jeunes générations, dans l'affirmation d'un individualisme aussi bien social que religieux.

2 Telle est l'ambition sous-jacente aux quinze contributions dont nous ne pouvons ici faire l'analyse exhaustive, mais qui illustrent pour la plupart une prise de distance à l'égard des constructions sociales de la réalité islamique. Nous citons à titre d'exemple quelques-unes des problématiques affrontées. 
3 M. Borrmans inaugure une perspective de recherche sur l'actuel travail herméneutique des musulmans par rapport à la Shari'a, porte d'ouverture au dialogue religieux mais aussi déconstruction de la «spécificité » statique de l'islam. E. Mayer démontre que la violation des droits de l'homme et les limites imposées à la citoyenneté ne sont pas l'apanage d'une «spécificité » islamique, mais la traduction de dérives nationalistes et politiques. Plusieurs contributions, à travers le prisme des rapports entre sécularisation et islamisme, mettent en lumière les points de rupture dans la conscience et la société musulmane. A. Filali-Ansari, à partir de l'analyse de l'œuvre du théologien Abd al-Raziq, souligne la complexité du rapport au politique, due davantage à une pratique historique qu'à un contenu de la croyance, la présence de la sécularisation ne s'étant pas accompagnée d'une Réforme capable de l'imposer à la conscience musulmane. M. Tozy analyse les relations entre le militantisme islamiste et les jeunes, (en particulier au Maroc), en soulignant la remise en question de la part des nouvelles générations de l'exclusivité de la compétence du clergé en matière d'exégèse, et l'abandon des solidarités familiales ou communautaires au profit de l'engagement social et religieux. F. Adelkhah et $\mathrm{F}$. Zabbal rappellent l'importance et l'originalité des mutations familiales, l'émergence de l'individualisme, en particulier féminin, trop souvent sous-estimé, et leur influence sur la transformation du champ religieux. Sur la scène européenne, dernier volet de l'ouvrage, J. Nielsen, à travers une analyse comparative de l'expérience de l'enseignement des religions, insiste, à juste titre, sur l'opportunité et la ressource sociales que représente pour un avenir multi-culturel, la demande de partenariat des musulmans d'Europe, confirmée par les conclusions de T. Ramadan sur les convergences éthiques et sociales entre musulmans et occidentaux.

4 La diversité des thèmes traités fait parfois perdre de vue l'idée centrale et fondamentale de l'ouvrage : restructurer le travail scientifique sur l'islam à partir d'une critique des constructions théoriques et méthodologiques opérées sur sa « spécificité ». 